\title{
EDUCATION AND EQUITY: THE CASE OF THE FÉNIX PROJECT FOR THE PROMOTION OF ACADEMIC ACHIEVEMENT
}

\author{
Carla Candeias ${ }^{1}$, Filipa Seabra', Marta Abelha ${ }^{1,2,3}$, Ana Sofia Mota ${ }^{4}$ \\ ${ }^{1}$ LE@D, Open University (UAb)(PORTUGAL) \\ ${ }^{2}$ Universidade Portucalense (PORTUGAL) \\ ${ }^{3}$ CEIS20 - University of Coimbra (PORTUGAL) \\ ${ }^{4}$ IJP, Universidade Portucalense (PORTUGAL)
}

\begin{abstract}
One of the primary missions of the school is to provide quality education to all students, regardless of their socioeconomic status, of the educational level of their parents or of their particular conditions and needs, thus contributing to greater equity. However, not all students are able to learn at the same pace and under the same conditions as the majority. The development of projects and actions dealing with academic failure and dropout is essential. In this context, in 2008, the Fénix Project (included in the Mais Sucesso Escolar Program) was created in the Portuguese educational setting, trying to promote equal conditions for success, contributing to an increasingly equitable school. The Fénix project is based on an organizational school model that facilitates more individualized support to students with learning difficulties in the subjects of Portuguese Language, Mathematics, or other subject identified by the school according to their success rates.
\end{abstract}

This article presents a case study implemented in a school cluster in the District of Setúbal that sought, through the implementation of the Fénix Project, to develop actions aimed at promoting school success among students from the four classes of the 5th grade. Three objectives were defined to respond to the research problem, respectively: i) to know the articulation, differentiation and curricular management practices of teachers involved in the Project; ii) to analyse the perceptions of students and teachers involved in the Project about its implementation and impact; and iii) to analyse the evolution of the academic results of the students participating in the Project.

In order to achieve the proposed objectives, a mixed research methodology was used: the application of a questionnaire survey to all students (166) and teachers (15) involved in the project, and a documental analysis of the academic results of the students involved in the project. Statistical analysis and content analysis were the selected data analysis techniques.

The main conclusions of the study point out that the Fénix Project was an asset, both for the majority of students involved, who considered that the Project contributed to their academic achievement (positive evolution of academic results), and for teachers, who reported having introduced curricular differentiation practices. A conclusion expected in the course of a project of this nature, especially in terms of students' assessment.

Keywords: Fénix Project; Pedagogical differentiation; Curriculum management; Academic achievement.

\section{INTRODUCTION}

The school needs to "reorganize itself, to overcome the challenge of welcoming all children and young people; to develop the basic curriculum" [1], offering everyone curricular diversification activities that facilitate pedagogical differentiation, enhancing equity. This pedagogical differentiation must happen through the promotion of diversified strategies, such as: grouping students according to different criteria; various support modalities; curricular reinforcement; level groups; project work; accompanied, guided and independent study. The greater the articulation between the pedagogical organization of the school and the management of curricular diversification activities is, the greater the quality of teaching.

In this sense, the Fénix Project (FP) emerges in 2008 in the Portuguese educational context, aiming to become an answer able to guarantee equal conditions of success in a School that is increasingly desired equitable. Improving students learning and decreasing dropout and school success are two of the main objectives of the FP. 
The FP is based on an organizational school model that makes it possible to give more individualized support to students who demonstrate learning difficulties in subjects like Portuguese Language, Mathematics, or others identified by the school, according to their success rate. Underlying the FP is, therefore, a "pedagogical strategy that implies that each student may have opportunities to increase their potential for success, which means high expectations concerning each of them" [2]. We can thus state that the FP was conceived to make a school for all, facing the problem of equity and educational inclusion.

The FP lays on three main principles, namely:

- Principle of relative homogeneity: temporary classes of relative homogeneity integrate students with specific learning difficulties in terms of Portuguese and Mathematics, with slower learning rates and with less consolidated learning. Students, who due to a diagnostic evaluation show more significant gaps in learning Portuguese and Mathematics, are sent to Ninhos (nests). Ninhos are considered educational support groups that temporarily accommodate students who need more intensive/specific/individualized support (usually not exceeding five to seven students per Ninho). These small groups work on different levels of content, not overloading the students' learning period since there is a simultaneous schedule between the Fénix and Ninho classes. The students who are part of Ninho, after an initial diagnosis made by the teacher of the Fénix class, have their permanence in Ninho regularly reassessed by Ninho / Fénix teachers of the intervened discipline.

Weekly, during a forty-five minutes period, Ninho students must return to Fénix classes, to interact with their classmates, through challenges and collaborative work, aiming for a broadened socialization and the measurement of consolidated learning.

- Principle of multidimensional success (school success understood in a multidimensional sense of student achievement): there is not only one, but several kinds of success and the school must be attentive to the promotion of the different dimensions of individual success, starting with academic, socio-emotional and relational, to behavioral. In this perspective, school action, as a teaching entity, is only possible using complementary and articulated knowledge, skills and processes, with the intervention of teachers and specialists in different areas.

- Principle of the school organization flexibility (curriculum and resources): it implies flexible management of human and physical resources, time (essential in a project that invests in differentiated learning rhythms), of class groups, as well as flexible management of the curriculum [2].

FP also requires that the school and its organization adjust to the needs of students, respecting the following purposes: i) the concept of success is plural; ii) the promotion of success must have an individual, organizational, social and family dimension; iii) promoting success is not "giving more of the same" in a logic of adding or surplus: It is providing learning differently, in the expected curriculum period; iv) the promotion of success must be linked to leadership, both transactional and transformational, and an ongoing continuous training strategy, centered on concrete action; and v) the participation of teachers, family and community in the construction of solutions and in the evaluation and adjustments is an essential condition [3].

In short, FP allows for remarkable plasticity and the ability to work in different ways. However, the big challenge should not be to consider equal opportunities as an end in themselves, but as something that will allow the mobility of resources and strategies, of "ways of teaching", of respecting and recognizing different rhythms of learning.

This article presents a case study about a Group of Schools in the District of Setúbal (Portugal) that sought, through the implementation of the Fénix Project, to develop actions aimed at promoting the academic success of students from eight classes of the 5th grade, whose average age was around 11 years old.

\section{METHODOLOGY}

The methodology adopted in this research assumed a mixed nature, that is, it combined characteristics from both quantitative and qualitative paradigm, as a way to take advantage of useful aspects from both paradigms, since it is intended to understand and describe a phenomenon, with the support of quantitative (questionnaire survey) and qualitative (documentary analysis) techniques. Concerning the qualitative approach, several written documents were analyzed, namely internal 
documents of the Group of Schools (ex. the Educational Project) and minutes of several meetings held (ex: the Fénix Group, the Curricular Department, the Pedagogical Council, the Disciplinary Group and the Class Council). Thus, we opted for the "use of bifocal lenses instead of a simple lens", in order to "combine empirical precision with descriptive precision" [4].

In this sense, this research came from the bifurcation between naturalistic approaches (qualitative or ethnographic), aiming for the description and understanding of a complex phenomenon, and rationalistic approaches (quantitative or experimental), as a complement in the collection and analysis of results (surveys and statistical analysis of students' academic results evolution). However, this article focuses essentially on the presentation and discussion of the questionnaire results, applied to all teachers $(\mathrm{N}=15)$ and students $(\mathrm{N}=166)$ involved in the Project, and on the school results of the students involved in the Project.

To what extent did the Fénix Project provide conditions to change teachers' practices, involving teachers in differentiated curriculum management and how has the school success of students taking part in the Project been evolving? was the research question to which we tried to find an answer.

To answer to this research problem, three research objectives were outlined, respectively: i) to know the articulation, differentiation and curricular management practices of the teachers involved in the Project; ii) to analyze the perceptions of students and teachers involved in the Project about its implementation and impacts; and iii) to analyze the evolution of the school results of the students participating in the Project.

Regarding the questionnaire survey data collection technique, which was applied to teachers participating in the FP, it was organized in three parts, namely: Part I - The influence of the school's top and middle management practices on the implementation of the Project (whose data will not be analyzed and discussed in this article); Part II - The practices of articulation, differentiation and curricular management of teachers involved in the FP and Part III - The perceptions of teachers involved in the FP on the implementation and impact of the project.

Concerning the questionnaire administered to students involved in the FP, it was structured in four parts: Part I - The implementation of the Fénix Project; Part II - School success; Part III - The integration in the class and the "Ninho" and Part IV - The teacher/student relationship.

The application of both questionnaires intended to find answers to the following questions, in a complementary way: How has the process of implementation of FP in the school involved progressed?; What are the top and intermediate management practices that influence the implementation of the Project?; How is pedagogical and curricular differentiation implemented in classrooms and the "Ninho"?; What strategies do classroom and "Ninho" teachers use to coordinate and articulate their practice?; What are the perspectives of students who participate in the FP on its implementation? And Was there an evolution in the learning of the students involved in the Project?

The data treatment technique used was the descriptive statistics analysis through the program Statistics Package for the Social Sciences: IBM - SPSS, version 22.

The documental analysis (of internal documents, minutes, meetings and agendas of school results) proved to be an essential element for data collection, as it was able to answer two of the objectives of the present investigation - to characterize the process of implementing the FP in a school in the District of Setúbal, as well as - to study the evolution of the academic results of the students participating in the FP.

The study intended to describe human relationships and activities (of students and teachers) involved in the implementation of the FP, thus allowing us to get to know meanings, motives, attitudes, beliefs, Etc. Thus, we decided to analyze minutes of the Class Council, Department, Disciplinary Group and the Fénix team, in order to understand how the teachers involved (from the Fénix class and the "Ninho" class) were able to manage and adapt their curriculum management practices, until then relatively private. At the same time, to comprehend how they developed ways of differentiating their work in the groups that were defined (those that stayed in the class and those that went to "Ninho").

A quantitative documental analysis of all the end of term classifications and evaluation grids of the classes involved was also performed, supported by statistical analysis. We sought to identify tendencies in the evolution of students' academic results in correlation to the implementation of the FP by the school. 


\section{RESULTS}

The presentation and discussion of the results are organized following the research objectives and part of the theoretical framework that underlies the present study.

\subsection{Characterization of the school cluster where the FP was implemented and of the participants in the study}

The studied School Group (SG) is located in a municipality where the majority of the population is from a disadvantaged socio-economic context, with an unemployment rate of around $14 \% .6 .5 \%$ of the population does not have any level of education, and 3.1\% lives on Social Integration Income.

The SG was created in September 2004, and consists of the following educational and teaching establishments: The Main-School, a kindergarten, three 1st cycle schools and a school with 2 nd and 3rd cycles of Basic Education.

Seven groups of pre-school education attend this SG (175 students), and about 1500 students are distributed among the 1st, 2nd and 3rd cycles of Basic Education (aged between 6 and 15 years old). The student population is culturally very diverse, with the integration of students from different countries, with a particular expression from those from African countries, whose official language is Portuguese, and Brazil. Educational failure in the School Group is over $20 \%$, and the dropout rate is around $6.4 \%$.

Regarding School Social Action (ASE), 48\% of students benefit from some economic support. Concerning information and communication technologies, $63 \%$ of students have a computer with internet access at home. The percentage of students with Special Educational Needs (SEN) is $9.5 \%$. In addition, according to data from the Quality Observatory of the School Group, a significant part of the students has learning difficulties, high levels of demotivation and disruptive behaviors within the school.

The teaching staff consists of 137 teachers, of whom only $20 \%$ are hired teachers (the remainder are «board teachers» with greater professional stability). The professional teaching experience is significant since $89 \%$ of teachers have been teaching for at least ten years. The non-teaching staff consists of 37 professionals, of whom 26 are operational assistants, 10 are technical assistants, and one is the Head of the School Administration Services.

The present study comprised 181 participants, of which: 166 are students attending the 5th grade (40.7\% female and $59.3 \%$ male) and 15 are teachers, who were involved in the FP.

\subsection{Answers to the research objectives (RO)}

\subsubsection{RO 1: to know the practices of articulation, differentiation and curricular management of teachers involved in the Fénix Project}

After analyzing the data from the questionnaire administered to teachers participating in the FP, it is possible to perceive a strong positive correlation between the item "I meet with colleagues of the same level and area to plan the classes" (to which $35.7 \%$ of respondents replied that "it always meets" and $28.5 \%$ replied that "it meets many times" and another $28.4 \%$ replied that "it meets from time to time" and only one respondent replied that "it meets only a few times") and the item "I disseminated/shared pedagogical differentiation strategies with colleagues" $(28.5 \%$ answered "always"; another $28.5 \%$ "often"; $21.4 \%$ "once a while" and only one teacher answered "few times" ). Thus, it is possible to conclude that the teachers, who were present in meetings to plan their work, tended also to be those who were most able to share the pedagogical differentiation strategies they developed, highlighting the importance of formal moments of planning activities together.

We also perceive that there is a strong positive correlation between the items "The FP had consequences in the way I planned and managed the curriculum, in non-Fénix classes" $(42.5 \%$ of the respondents replied that they neither agree nor disagree) and "I applied different assessment instruments according to the different levels of proficiency" ( $57.1 \%$ of the teachers answered that they fully agree). The items "Depending on the school results that I obtained, I adapted the teaching methodologies", "I take into account what the student already knows about certain content, to decide the methodology with which I will approach it" (to these two statements the respondents answered in the same way: $57.1 \%$ affirm that they fully agree and $42.9 \%$ partially agree), "I used different materials 
according to student proficiency levels" (37.7\% fully agree and $64.3 \%$ partially agree) and "The FP made me resource to individualized teaching" (50\% partially agree and $35.7 \%$ fully agree).

Regarding these results, we found more positive and less positive aspects. In terms of assessment, a large number of teachers considers having performed a diversified practice, and in terms of defining teaching methodologies, there is a resource to the students' prior knowledge. However, there is less consensus regarding the use of different materials and the resource to individualized teaching (although there is still a majority of concordant responses). These changes, though, do not appear to have had an evident impact on the way teachers work with classes not involved in the project. We also emphasize that the percentage of concordant responses is not indicative of unanimity, which again reflects the existence of teachers whose understanding of the project and curricular and pedagogical practices are not in line with what would be expected.

The existence of these correlations, at the same time, points to a project in which the various elements were articulated with each other, with emphasis on the assessment instruments, methodologies and planning.

Thus, there may be an advancement towards more differentiated curricular work, which recognizes that "[...] life experiences and the socio-cultural environment are obviously key ingredients of the person we are, of our sense of self" [5].

\subsubsection{RO 2: to analyze the perceptions of students and teachers involved in the Project about its implementation and its impact}

Regarding teaching practices and the teacher-student relationship, is possible to conclude that, from the teachers' point of view, the FP contributed to improve the existing relationship between teacher and student, possibly related to the fact that these two groups, class and "Ninho" are reduced in number. Teachers could more easily "reach" all students, even those who had difficulties in exposing their doubts. For $50 \%$ of the surveyed teachers, it was possible to apply a differentiated pedagogy. In the same line of thought, most of the students surveyed stated that they managed to establish a closer relationship with the teacher and to obtain more individualized feedback, with $58 \%$ of the students saying to be satisfied with the FP.

Regarding the relationship between teachers, the study shows that for $71.4 \%$ of teachers the FP contributed to the improvement of their relationship, as internal communication improved, a consequence of the collaborative work developed among teachers who shared and reflected together on the teaching and learning processes.

Concerning the active participation of students in the classroom, $73 \%$ of teachers consider that it has increased both in terms of "Ninho" and class, which may be a reflection of the reduced number of students (maximum 7), at the same level of learning. Thus, students were not inhibited from participating by asking questions and responding actively.

Regarding the continuity of the FP, for $85.7 \%$ of the teachers "the school must maintain the FP, for the next school year" and that "the implementation of the FP, in the grouping of schools, was a well taken decision to fill the high rate of school failure" $(57.7 \%$ of teachers totally agree with this statement and $14.3 \%$ partially agree). These results allow us to conclude that teachers consider that the FP was a good option to answer the school failure rate, and that it must be continued in the 5th grade and 6th grade classes. Teachers also think that FP should extend to other subjects whose failure rate proves to be high.

Summing up, it can be said that the FP is inserted in a school "that thinks itself, does not ignore its problems, on the contrary, it involves "all its members" in the decision-making and resolution processes, recognizing, in this way, the "learning that results for them" [6].

By analyzing the data from the questionnaire administered to the students, strong positive correlations were observed between several items and the item referring to "satisfaction with the FP", namely: "The classes at Ninho are more interesting" (69,1\% of the students agrees with the statement); "Since I entered Ninho I have improved my results" (67,9\% of the students agree with the statement); "I feel that I am a better student since I attend Ninho" (51,9\% of students agree with the statement); "Ninho helped me to understand the subject better" ( $70.2 \%$ of students agree with the statement); "I feel integrated in Ninho" $69,1 \%$ of the students agree with the statement); "Since I am in the FP, I feel supported because I can count on the help of more than one teacher" $(77,8 \%$ of students agree with this statement). Thus, we conclude that students who consider that classes in Ninho are more interesting are the ones who feel most supported and integrated. They also consider the most 
effective intervention in terms of understanding and academic results, and they express the most satisfaction about the Project as a whole; This brings us to the idea that the creation of this Project and its implementation in public schools reflects a lot of what the school should be: "innovative and solidary. It must create the conditions to awaken expectations in all students, wherever they come from and whatever their situation" [7]. The positive perception of the more significant support on the part of the teachers stands out, which may contribute to the fact that the class and Ninho teachers frequently work in close partnership, allowing the group of students to remain for some time in the class and in Ninho. Students feel well and integrated in both places (class and Ninho) which may have contributed to the students' satisfaction throughout the development of the FP.

\subsubsection{RO 3: to analyze the school results development of students participating in FP}

By analyzing, the data on the school results of the students participating in the Project, the results by subject were also examined. It should be noted that the grades given at the end of each school term may be between level 1 (considered negative) and level 5 (considered very good).

Regarding the Portuguese Language subject and using analysis of frequencies, it was observed that no student had a level 1 grade and that the students from the 1st to the 3rd period increased their grades, with only 4 students with a negative grade (grade 2 ). The failure rate went from $8,4 \%$ in the first period to a rate of $4,1 \%$ at the end of the school year. For level 5 students, the success rate increased by $3 \%$. This improvement may be due to a plurality of factors. However, as the pilot year of implementation of the project was concomitant, it encouraged the school management to keep the work started, hoping that this promising improvement would continue in the future.

Analyzing Mathematics, the results obtained over the three periods in which the pilot implementation of the FP took place; there was also a positive development in the students' school results.

The percentage of failure in the 1 st term was $32,6 \%$, decreasing to $18,6 \%$ at the end of the school year. There was no significant difference between the highest levels (4 and 5 ), but rather in the transition from level 2 (negative) to level 3 (positive). These results suggest a possible effect of the implementation of the FP (which we cannot categorically state, as many other factors may have played an essential role in the evolution of the results) especially in terms of the recovery of students with greater difficulties. The quality of success has not yet registered a positive evolution in this subject, and the failure rate, although much lower, remains at a high level, which encourages reflection and deepening of the proposed improvements.

By analyzing the retention and dropout rates over the last 3 years, there was a decrease from $30,73 \%$ to $14,45 \%$. This fact was concomitant with the implementation of the FP that sought to encourage more motivating practices for students who were at risk of dropping out of school and in a situation of possible retention. Through Ninho these students had more individualized support, respect for their learning rhythms in order to recover learning and increase their motivational levels. Besides, a closer relationship between teachers and students may have contributed to the decrease in dropout during this period.

In short, the FP aspired to invest in learning in the 5th year of school, promoting:

i) the capacity of each student, taking into account the different their learning rhythms and creating smaller groups: Ninhos and ii) diversified and personalized teaching and learning strategies to facilitate a reduction on school failure and dropout.

In terms of the teachers' work dynamics, collaborative work practices were privileged, joint reflection, sharing and building a culture of commitment that had an impact on the increase of teaching professionalism levels.

\section{CONCLUSIONS}

Recollecting the research problem of this study: To what extent did the FP provide conditions for the change of teachers' practices, by involving teachers in the differential management of the curriculum and how has the school success of the students involved in the FP, in the school in question? we can conclude that the FP has been implemented:

- gradually and without the imposition of leadership structures (either top or middle);

- through horizontal curricular articulation practices, among the teachers involved, encouraging collaborative work; 
- following flexible curriculum management and differentiated pedagogy;

- adapting the curriculum to students' proficiency levels.

Most of the interviewed teachers agreed that the FP was an asset for the educational success of the students and that it should continue in the following school year. A majority of students felt well integrated into Ninho, and that this strategy had contributed to their success. The teachers also reported having introduced differentiation practices, as would be expected in the course of a project of this nature, especially in terms of students' assessment.

We can see the positive recognition on the part of the different the FP participants, at the level of several domains, namely in the questions of evaluation, pedagogical differentiation, the relationship among teachers and between teachers and students. There was also an improvement in the students' academic results on Portuguese and Mathematics and a decrease in the dropout rate. However, some dimensions still require reflection and improvement, a more sustained improvement in the quality of success, the achievement of defined goals, a better articulation and identification of common practices to be developed by teachers within the scope of the FP, referring to greater coordination and articulation of teaching practices.

\section{REFERENCES}

[1] J. Formosinho and J. Machado, "A cidadania e a Democracia nas escolas." ELO. Revista do Centro de Formação Francisco de Holanda, vol. 18, pp.15-26, 2012. Retrieved from http://cffh.pt/userfiles/files/ELO\%2018.pdf\#page=16

[2] J. Azevedo, D. Gonçalves, D. Gonçalves, J. L. Silva, C. Nogueira, I. C. Sousa, J. Moreira and L. Tavares, $O$ que desencadeia o sucesso em alunos com baixo rendimento escolar, no Projeto Fénix. Porto: Escola Superior de Educação Paula Frassinetti e Universidade Católica Portuguesa, 2014.

[3] L. T. Moreira, Projeto Fénix: Sentidos de um projeto emergente na constituição do sucesso escolar. Porto: Universidade Católica do Porto, 2004.

[4] J. R. S. Fonseca, Os Métodos Quantitativos na Sociologia: Dificuldades de Uma Metodologia de Investigação," in Mundos socias: Saberes e Práticas. VI Congresso Português de Sociologia, Universidade Nova de Lisboa. Faculdade de Ciências Sociais e Humanas, 2008.

[5] I. F. Goodson, "Dar voz ao professor: as histórias de vida dos professores e o seu desenvolvimento profissional," in Vidas de Professores (A. Nóvoa), pp. 63-78, Porto: Porto Editora, 2007.

[6] I. Alarcão, Escola reflexiva e supervisão: uma escola em desenvolvimento e aprendizagem. Porto: Porto Editora, 2000.

[7] J. Sebarroja, A aventura de inovar: a mudança na escola. Porto: Porto Editora, 2001. 